\title{
PROSEDUR PELAKSANAAN KREDIT USAHA RAKYAT (KUR) PADA PT. BANK NAGARI CABANG PADANG
}

\author{
DEO PRATAMA, JHON FERNOS \\ Akademi Keuangan Perbankan "Pembangunan" Padang \\ Jhonfernos@akbpstie.ac.id
}

\begin{abstract}
PT. Bank Nagari Cabang Padang is one of the banks that provide People's Business Credit (KUR) facilities up to Rp.500,000,000, - which will be channeled to the business development sector, within a maximum credit period of up to 5 years. In distributing credit to prospective borrowers, PT. Bank Nagari Cabang Padang uses 7P Analysis method, namely Personality, Party, Purpose, Prospect, Protection, and Profitability. And PT. Bank Nagari Cabang Padang also uses 5C analysis, namely Character, Capacity, Capital, Condition of Economy and Collateral. Procedures for granting people's business loans to PT. Bank Nagari Cabang Padang are among others, first, prospective borrowers apply for credit. second, the marketing department checks the completeness of the document. Third, conduct a business location review. Fourth, if credit is agreed, the legal officer will be given an order to the notary section and a notary credit agreement is made, only after that is a credit search.
\end{abstract}

Keywords : implementation procedure, Kredit Usaha Rakyat (KUR), Bank Nagari

\section{PENDAHULUAN}

Bank adalah salah satu lembaga keuangan yang ada di Indonesia yang mempunyai peran penting bagi kelangsungan perekonomian Indonesia. Bank juga merupakan lembaga keuangan yang kegiatan utamanya menghimpun dan menyalurkan dana dari masyarakat, dalam bentuk simpanan Giro, tabungan dan Deposito kemudian menyalurkan dana dalam bentuk kredit bagi masyarakat yang membutuhkannya. Setelah itu bank juga sebagai tempat untuk menukar uang, memindahkan uang dan menerima pembayaran dalam segala bentuk, mulai dari pembayaran listrik, telepon, uang kuliah, dan lainnya.

Bank sangat amat dibutuhkan masyarakat oleh karena itu aktivitas dan penyelenggaraan kegiatan perbankan harus secara selaras, teratur dan terencana mengacu kepada kebijakan dan peraturan yang dikeluarkan oleh Pemerintah, khususnya Peraturan Bank Indonesia (Suhardi, 2016).

Berdasarkan undang-undang no.7 tahun 1992 tentang Perbankan, fungsi utama perbankan adalah sebagai penghimpun dana dan penyalur dana pada masyarakat dalam bentuk kredit.

Kredit merupakan penyediaan uang atau tagihan yang dapat disamakan dengan itu, yang berdasarkan dengan persetujuan atau kesepakatan pinjam-meminjam antara pihak bank dengan pihak lain yang mewajibkan pihak peminjam untuk melaksanakan kembali pembayaran dengan jumlah yang telah di tetapkan sesuai dengan jumlah bunga, imbalan atau pembagian hasil dan keuntungannya (Cahyono, 2010). 
Sedangkan menurut (Amanda, 2015) Kredit adalah sumber utama penghasilan bagi bank yang merupakan sekaligus sumber operasi terbesar, sebagian besar dana operasional diputarkan dalam bentuk kredit. Bila kegiatan tersebut berhasil maka usaha bank pun berhasil. Namun bila bank banyak terjerat kredit bermasalah, hal ini akan berpengaruh besar bagi operasional bank.

Kredit yang akan diberikan berdasarkan kepada kepercayaan. Sehingga sama dengan demikian, pemberian kredit merupakan pemberian kepercayaan. Ini berati bahwa bank akan memberikan kredit kalau ia benar-benar yakin bahwa si penerima kredit akan mengembalikan pinjaman yang diterimanya sesuai dengan jangka waktu dan syarat-syarat yang telah disetujui oleh kedua belah pihak (Kasmir, 2014).

Kebijakan KUR baru dimulai dengan adanya keputusan Rapat Kabinet Terbatas yang diadakan pada tanggal 9 Maret 2007 bertempat di Kantor Kementerian Negara Koperasi dan Usaha Kecil Menengah (UKM) yang kala itu masih dipimpin Bapak Presiden RI Susilo Bambang Yudhoyono. Dalam sidang tersebut salah satu kebijakan yang diambil kala itu adalah, bahwa sebagai salah satu bentuk upaya pengembangan usaha Usaha Mikro Kecil, Menengah (UMKM) dan koperasi, pemerintah akan mendorong peningkatan akses pelaku UMKM dan koperasi kepada kredit atau pembiayaan melalui perbankan dengan peningkatan kapasitas Perusahaan Penjamin. Kredit Usaha Rakyat digulirkan pada masa pemerintahan Presiden Susilo Bambang Yudhoyono pada tanggal 5 November 2007 kemudian didukung oleh Instruksi Presiden No. 5 Tahun 2008 tentang Fokus Program Ekonomi Tahun 2008 - 2009 untuk menjamin implementasi atau percepatan pelaksanaan KUR ini, berbagai kemudahan bagi pelaku kegatan UMKM pun ditawarkan oleh pemerintah. Beberapa di antaranya adalah tentang bagaimana penyelesaian kredit bermasalah UMKM. Ketetapan Mentri keuangan No 135/PMK.05/2008 tentang fasilitas penjaminan KUR. Supaya kredit yang diberikan tersebut lancar, maka pihak bank harus selektif dalam memberikan kredit pada kreditur, dimana sebelum kredit di berikan kepada debitur maka pihak bank harus menganalisa pemberian kredit tersebut untuk menentukan kesanggupan kreditur membayar kembali pinjaman sesuai dengan persyaratan yang terdapat dalam perjanjian pinjaman tersebut. Oleh karena itu, bank harus bisa menetapkan prosedur atau proses pelaksanaan kredit serta mengantisipasi masalah-masalah yang timbul terhadap kredit macet. Karena itu akan berpengaruh pada aktivitas perbankan itu sendiri terutama terhadap kerja operasional bank dalam penyaluran kredit untuk kesejahteraan masyarakat.

Maksud dan tujuan pemerintah atas kebijakan KUR untuk mempercepat pengembangan yang benar serta pemberdayaan UMKM, dalam mengangkat akses pembiayaan kepada UMKM, Koperasi sebagai mengatasi kemiskinan dan membuka peluang kesempatan kerja (Wijaya, 2016).

Kredit Usaha Rakyat (KUR) adalah kredit atau pembiayaan kepada Usaha Mikro Kecil Menengah (UMKM) dalam bentuk pemberian modal kerja dan investasi yang didukung oleh fasilitas penjaminan untuk usaha produktif dan layak (feasible) namun mempunyai keterbatasan dalam pemenuhan persyaratan yang ditetapkan oleh perbankan (Widiastuti, 2017).

Sedangkan menurut (Haryana, 2014) sasaran pelaksanaan dari program KUR adalah golongan masyarakat yang telah diberikan pelatihan yang terus ditingkatkan dalam pemberdayaan serta kemandiriannya pada alokasi program 
sebelumnya. keinginanya agar kelompok masyarakat tersebut mampu untuk memanfaatkan skema pendanaan yang berasal dari lembaga keuangan formal seperti Bank, Koperasi, BPR dan sebagainya. Melihat dari sisi kelembagaan, maka sasaran KUR adalah UMKMK (Usaha Mikro, Kecil, Menengah dan Koperasi). Sasaran utama pelaksanaan KUR adalah semua sektor usaha yang menghasilkan (produktif).

Dengan ditetapkannya Peraturan pelaksanaan KUR berikut dengan beberapa kebijakan pendukungnya, maka pemrintah mengharapkan dengan penyaluran KUR oleh Bank Nagari dapat dijalankan dengan baik dan didukung serta pelaksanaan sepenuhnya oleh setiap pejabat hingga rencana penyaluran KUR tersebut dapat direalisir sebagaimana yang diharapkan.

Berdasarkan uraian diatas, maka penulis tertarik untuk membahas lebih lanjut mengenai "Prosedur Pelaksanaan Kredit Usaha Rakyat (KUR) Pada Bank Nagari Cabang Padang”.

\section{METODE PENELITIAN}

\section{Metode Pengumpulan Data}

1. Studi Lapangan (Field Research)

Peninjauan langsung ke objek penelitian yang dipilih untuk meneliti hasil data tersebut. Penelitan langsung ke lapangan ini akan dapat membantu penulis untuk melengkapi data yang diperlukan. Adapun cara riset lapangan ini adalah dengan mewawancarai langsung pihak-pihak yang berkepentingan dalam hal ini adalah perusahaan yang terkait.

2. Studi Perpustakaan (Library Research)

Penelitian ini dilakukan ke perpustakaan berupa buku-buku ilmiah dan tulisan-tulisan yang berhubungan dengan pembahasan yang dilakukan.

\section{Metode Analisa Data}

Dalam menganalisa data, penulis menggunakan analisa data kualitatif. Dimana metode kualitatif menggambarkan, memahami dan menjelaskan data yang diteliti selama penelitian berlangsung mengenai pelaksanaan prosedur Kredit Usaha Rakyat (KUR) pada Bank Nagari Cabang Padang.

\section{Prosedur Pelaksanaan Kredit Usaha Rakyat (KUR) Pada Bank Nagari Cabang Padang}

Berdasarkan penelitian mengenai prosedur pelaksanaan kredit usaha rakyat (KUR)

Cabang Padang maka dapat di tarik kesimpulan sebagai berikut:

1. Para calon debitur yang ingin mendapatkan fasilitas kredit dari Bank Nagari Cabang Padang terlebih dahulu mengajukan permohonan tertulis serta melengkapi persyaratan yang ditentukan oleh pihak bank. Semua lampiran permohonan yang telah lengkap persyaratannya maka akan dianalisa oleh account officer atau analis kredit dan dianalisa lebih lanjut seperti survey kelapangan dan proses analisa menggunakan konsep 5C dan 3R. Account officer nantinya akan melaporkan hasil analisanya pada komite kredit untuk dibahas apakah permohonan kredit tersebut diterima atau ditolak. Direktur akan mengesahkan permohonan kredit yang disetujui dalam rapat komite 
kredit. Untuk selanjutnya antara bagian administrasi kredit dengan debitur dapat melakukan perjanjian kredit, dan setelah itu dilanjutkan dangan realisasi atau pencairan kredit. Kemudian pihak bank melakukan penagihan tiap bulannya baik melalui pemotongan dana langsung dari rekening debitur atau autodebet maupun penagihan tunai langsung kepada debitur sampai saat pelunasan kredit, dan diakhiri dengan pengembalian agunan kredit.

2. Permasalahan yang timbul dalam pelaksanaan pemberian kredit usaha rakyat (KUR) pada Bank Nagari adalah kredit macet atau bermasalah. Faktor yang menyebabkan kredit bermasalah adalah kurang telitinya pihak bank dalam melaksanakan atau melakukan peninjauan atas analisa kredit, serta faktor menurunnya usaha debitur kredit usaha rakyat. Upaya-upaya yang dilakukan oleh pihak Bank Nagari, yaitu Bank Nagari Cabang Padang dalam mengatasi kredit bermasalah dengan dilakukan penagihan secara terus-menerus yang bersifat persuasif.

3. Sebelum kredit usaha rakyat disalurkan kepada masyarakat, Bank Nagari terlebih dahulu menentukan kriteria calon debitur yang bisa menerima atau yang berhak mengajukan permohonan Kredit Usaha Rakyat sektor pertanian pada Bank Nagari Cabang Padang. Adapun kriteria calon debitur kredit usaha rakyat mikro dan ritel adalah sebagai berikut:

a. Perorangan

1) Warga Negara Indonesia yang telah berusia 21 tahun atau yang telah menikah, berada dalam proses pengampunan/curatele.

2) Memiliki usaha produktif pada sektor pertanian.

3) Anggota keluarga karyawan/karyawati yang memiliki penghasilan tetap atau bekerja sebagai Tenaga Kerja Indonesia.

4) Pekerja yang terkena pemutusan hubungan kerja (khusus KUR mikro).

5) Usaha produktif atau karyawan/karyawati yang bekerja harus telah berjalan selama 6 bulan.

6) Data calon debitur harus terdapat dalam Sistem Informasi Kredit Program (SIKP).

7) Calon debitur tidak mempunyai riwayat kredit dengan kualitas nonlancar di bank atau lembaga lainnya.

8) Calon debitur yang memiliki kredit perumahan, kepemilikan motor, serta KUR mikro harus memiliki kolektibilitas lancar.

9) Calon debitur yang masih memiliki baki debet kredit/pembiayaan produktif yang tercatat dalam informasi debitur (SID) tapi telah melunasinya, maka calon debitur harus menyerahkan surat keterangan lunas atau surat roya dengan lampiran cetakan rekening kredit yang telah dilunasi.

\section{Prosedur Penyaluran Kredit Menurut Bank Indonesia Pasal 1 Undang- undang No. 10 Tahun 1998}

Agar penyaluran kredit dapat diwujudkan dengan menerangkan alur proses administrasi sehingga dan debitur memperoleh kredit terlebih dahulu harus melalui tahapan-tahapan penilaian mulai dari pengajuan proposal kredit dan dokumen yang diperlukan, melihat keaslian dokumen, melakukan analisis kredit sampai dengan kredit dikucurkan. Bagian-bagian penilaian dalam pemberian kredit ini merupakan prosedur pemberian kredit. Tujuan penetapan prosedur 
pemberian kredit untuk memininimalisir rresiko kredit dan untuk memastikan kelayakan agar suatu kredit diterima atau ditolak. Dalam prosesnya prosedur pemberian kredit secara keseluruhan dapat dibedakan menjadi pinjaman yang dilakukan perorangan dan pinjaman oleh suatu kelompok berbadan hukum. Proses penyaluran Kemudian dapat pula ditinjau segi tujuannya kredit dibedakan menjadi kredit konsumtif atau produktif.

Menurut bank Indonesia pasal 1 Undang-Undang No. 10 tahun 1998 pemberian kredit merupakan kegiatan utama bank yang mengandung resiko yang dapat berpengaruh pada kesehatan dan kelangsungan usaha bank. Namun mengingat sebagai lembaga intermediasi, sebagian besar dan bank berasal dari dana masyarakat, maka pemberian kredit perbankan banyak dibatasi oleh ketentuan undang-undang dan ketentuan bank Indonesia.

Sebagaimana Undang-Undang Perbankan telah mengatur agar bank selalu berpegang kepada prinsip kehati-hatian dalam melaksanakan kegiatan usahanya, salah-satunya didalam penyaluran dana kredit. seterusnya, Bank Indonesia sebagai otoritas perbankan juga telah menetapkan peraturan-peraturan dalam pemberian kredit oleh perbankan. Diantara regulasi dimaksud antara lain adalah regulasi mengenai kewajiban Penyusunan dan Pelaksanaan Kebijaksanaan Pengkreditan Bank bagi bank Umum, Batasan penyaluran dana Kredit, Penilaian bobot Aktiva, Sistem Informasi Debitur, serta pembatasan lainnya dalam pemberian kredit.

1. Kewajiban Penyusunan dan Pelaksanaan Kebijaksanaan Pengkreditan

Supaya penyaluran kredit dapat dilaksanakan secara konsisten dan berdasarkan azas-azas perkreditan yang baik dan benar, maka diteapkan suatu kebijakan dalam perkreditan yang tertulis. Berkaitan dengan hal tersebut, Bank Indonesia telah memutuskan dan menetapkan ketentuan yang harus dipenuhi mengenai kewajiban bank umum untuk memiliki dan melaksanakan kebijakan pengkreditan bank dalam SK Direksi Bank Indonesia No. 27/162/KEP/DIR tanggal 31 Maret 1995.

Berdasarkan SK Direksi Bank Indonesia tersebut, Bank Umum wajib memiliki kebijakan perkreditan bank secara tertulis yang disepakati oleh dewan komisaris bank dengan sedikitnya memuat dan mengatur hal-hal pokok berikut:

a. Dokumentasi dan administrasi kredit

b. Pengawasan kredit

c. Penyeleseaian kredit bermasalah

d. Prinsip kehati-hatian dalam perkreditan

e. Organisasi dan manajemen perkreditan

f. Kebijakan persetujuan kredit

Kebijakan perkreditan bank dimaksud wajib disampaikan kepada Bank Indonesia. Didalam pelaksanaan pemberian kredit dan pengelolah perkreditan bank wajib menuruti kebijakan perkreditan bank yang telah ditetapkan secara konsekuen dan konsisten.

2. Prosedur pemberian kredit yang ditetapkan dalam peraturan Bank Indonesia
a. Mengisi formulir aplikasi kredit
b. Melengkapi persyaratan
c. Data historis perusahaan
d. Data proyeksi
e. Data jaminan 
f. Mengecek apakah formulir permohonan dan dokumen yang diperlukan sudah lengkap

g. Penyerahan dokumen ke bank

h. Konfirmasi data/ dokumen

i. Analisa kelayakan kredit dengan menggunakan 5C

j. Analisis keuangan

k. Persetujuan kredit

\section{Hambatan-hambatan dalam Proses Pembelian Kredit Usaha Rakyat (KUR)}

Hambatan yang terjadi dalam proses pemberian kredit kepada masyarakat yang berpenghasilan tetap (KUR) berupa kurangnya sosialisasi kelapangan sehingga masih banyak masyarakat yang tidak mengetahui bahwa kredit pegawai ada di PT. Bank Nagari Cabang Padang dan kurangnya kelengkapan persyaratan yang diserahkan nasabah sehingga proses untuk realisasi terhambat.

PT. Bank Nagari Cabang Padang pada proses pemberian KUR mengalami masalah berupa radius nasabah dari bank penyalur KUR cukup jauh, data SID (Sistem Informasi Debitur) nasabah yang punya pinjaman lain dalam kondisi Non Lancar, masyarakat mendapatkan bantuan pemerintah daerah, masyarakat mendapatkan fasilitas pinjaman dari pemerintah daerah dan Kredit Usaha Rakyat (KUR) tidak cuma disalurkan oleh PT. Bank Nagari Cabang Padang namun juga banyak disalurkan oleh bank-bank lainnya.

Cara mengatasi hmbatan yang dihadapi PT. Bank Nagari Cabang Padang dalam pemberian kredit kepada masyarakat yang berpenghasilan tetap (Kredit Pegawai) dan tidak berpenghasilan tetap (KUR) yang telah terjadi yaitu dengan melakukan sosialisasi kelapangan terutama kelokasi yang berjauhan dari kantor PT. Bank Nagari Cabang Padang beserta menyebarkan brosur ke kantor/instansi/sekolah serta memasang spanduk tentang Kredit Pegawai beserta ketentuan dan persyaratan secara lengkap.

Salah-satu upaya yang ditetapkan oleh PT. Bank Nagari Cabang Padang untuk mengatasi halangan pada proses penyaluran KUR yang terjadi yaitu dengan meningkatkan mutu pegawai agar lebih kreatif dalam menawarkan produk pinjaman kepada nasabah, melakukan sosialisasi ke nasabah agar terjalinnya hubungan baik antar nasabah dengan pihak bank dan memasang spanduk dan menyebar brosur tentang Kredit Usaha Rakyat (KUR) beserta ketentuan dan persyaratan secara lengkap.

\section{Pembahasan}

Sesuai dengan ketetapan Menteri Keuangan Nomor 135/PMK.05/2008 mengenai Fasilitas Penjaminan Kredit Usaha Rakyat, pengertian KUR adalah "kredit atau pembiayaan kepada UMKMK dalam bentuk penyaluran dana untuk modal kerja dan investasi yang didukung fasilitas penjaminan untuk usaha produktif'.UMKM adalah usaha produktif yang layak (feasible), namun belum bankable. KUR mensyaratkan bahwa jaminan pokok kredit adalah proyek yang dibiayai. Akan tetapi agunan tambahan yang dimiliki oleh UMKM pada umumnya kurang, maka sebagian agunan di-cover dengan program penjaminan. Maksimal coverage penjaminan adalah sebanyak $70 \%$ dari plafond kredit. Sumber dana KUR sepenuhnya berasal dari dana komersial Bank. 
Perguliran KUR merupakan tindak lanjut dari ditandatanganinya nota kesepahaman bersama (MoU) pada tanggal 9 Oktober 2007 tentang Penjaminan Kredit/ Pembiayaan kepada UMKMK antara Pemerintah (Menteri Negara Koperasi dan UKM, Menteri Keuangan, Menteri Pertanian, Menteri Perindustrian, Menteri Kehutanan, Menteri Kelautan dan Perikanan, Perusahaan Penjamin (Perum Sarana Pengembangan Usaha dan PT. Asuransi Kredit Indonesia) dan Perbankan (BRI, Bank Mandiri, Bank Bukopin, BNI, BTN, dan Bank Syariah Mandiri). KUR ini didukung oleh Kementrian Negara BUMN, Kementerian Koordinasi Bidang Perekonomian, serta Bank Indonesia Penggolongan KUR Sejak diluncurkan oleh Presiden Susilo Bambang Yudhoyono pada tanggal 5 November 2007, KUR ditawarkan dengan berbagai pilihan, yaitu :

1. KUR s/d Rp 500 juta

2. KUR (Mikro) s/d Rp 5 juta

3. KUR Lingkage Program

Disamping itu dengan banyaknya pertanyaan mengenai prosedur dan ketentuan Suplesi untuk KUR Mikro, maka dapat dijelaskan bahwa sebanding dengan ketentuan yang tercantum pada SE Direksi Nose.S.09-DIR/ADK/03/2010 Tanggal 18 Maret 2010, telah disepakati bahwa kepada calon debitur KUR Mikro dapat diberikan suplesi dengan ketentuan "total eksposur pinjaman maksimal Rp.5 juta". Seiring dengn hal itu, mengingat bahwa hingga sampai sekarang ini maksimal plafond Kredi Usaha Rakyat (KUR) Mikro telah menjadi Rp. 20.000.000 sebanding dengan ketentuan yang diatur melalui Nofacs Kanpus BRI No.B.146-MKR/KPM/10/2010 tanggal 15 Oktober 2010, maka Suplesi KUR Mikro dapat diberikan dengan total eksposur menjadi maksimal Rp. 20.000.000.

\section{Simpulan Dan Saran}

\section{Simpulan}

Berdasarkan hasil pembahasan dari data yang diperoleh melalui observasi, wawancara, dan pertanyaan yang diajukan oleh peneliti kepada pihak-pihak yang berkepentingan dalam penelitian ini, maka peneliti dapat mengambil kesimpulan sebagai berikut:

1. PT. Bank Nagari Cabang Siteba adalah salah satu bank yang memberikan fasilitas Kredit Usaha Rakyat (KUR) hingga mencapai Rp.500.000.000,- yang akan disalurkan kepada sektor pengembangan usaha, dalam masa tenggak waktu kredit maksimal sampai dengan 5 tahun.

2. Dalam menyalurkan kredit kepada calon debiturnya, PT. Bank Nagari Cabang Siteba menggunakan metode Analisis 7P yaitu Personality, Party, Purpose, Prospect, Protection, dan Profitability. Dan PT. Bank Nagari juga menggunakan analisis 5C yaitu Character, Capacity, Capital, Condition of Economy dan Collateral.

3. Prosedur pemberian kredit usaha rakyat pada Bank Nagari antara lain yaitu pertama, calon debitur mengajukan permohonan kredit. kedua, bagian marketing memeriksa kelengkapan dokumen. Ketiga, melakukan tinjauan kelokasi usaha. Keempat, jika disetjui kredit akan diberikan kebagian legal officer untuk dilakukan order kepada bagian notaris dan dibuatkan surat perjanjian kredit oleh notaris, baru setelah itu dilakukan pencarian kredit. 
4. Potensi nasabah KUR khususnya BPD Cabng Siteba sangat besar, hal ini diperlihatkan dari data perkembangan jumlah nasabah dari nilai KUR yang ada pada tahun 2017-2018.

\section{Saran}

Dari uraian diatas penulis memberikan saran antara lain:

1. Agar PT. Bank Nagari Cabang Siteba dapat lebih mensosialisasikan tentang fasilitas Kredit Usaha Rakyat ini kepada seluruh masyarakat khususnya di kecamatan Siteba, supaya masyarakat dapat leih memahami tentang bagaimana prosedur Kredit Usaha Rakyat.

2. Agar PT. Bank Nagari Cabang Siteba lebih memperhatikan pelayanan kredit terhadap calon debitur agar calon debitur dapat merasa nyaman dalam melakukan peminjaman kredit.

3. Agar Pemerintah dapat menekan kembali tingkat bunga pada kredit KUR, karena merupakan kebijakan pemerintah untuk menyokong pertumuhan ekonomi melalui pembiayaan bagi pelaku ekonomi mikro, kecil, menengah, dan koperasi.

\section{UCAPAN TERIMA KASIH}

Dengan menyebut nama ALLAH SWT yang Maha Pengasih Lagi Maha Penyayang, penulis ucapkan puji dan syukur atas kehadirat-NYA, yang telah melimpahkan rahmat, hidayah kepada saya. Penulis ingin menyampaikan terima kasih yang tak terhingga atas bimbingan bapak Romi Susanto, SE.MM yang telah memberikan motivasi, masukan - masukan maupun terima kasih untuk semangat dan dukungannya yang sangat berguna untuk Tugas Akhir. Akhir kata penulis ucapkan terima kasih, semoga apa yang penulis tuangkan dalam karya kecil ini memberikan manfaat terutama bagi saya sendiri selaku penulis. Amin ya Rabbal'alamin.

\section{DAFTAR PUSTAKA}

Alanshari, F., \& Marlius, D. (2018). Prosedur Pemberian Kredit KPR Pada PT. Bank Tabungan Negara (Persero) TBK Cabang Pembantu Bukittinggi. https://doi.org/10.31227/osf.io/rsfhc

Amanda, Praiselia. 2015. "Kajian Penyaluran Kredit Usaha Rakyat (Kur) Pertanian Pada Bank Bri Kantor Cabang Tondano." In Skripsi Fakultas Pertanian Universitas Sam Ratulangi Manado, , 6.

Arumsari, Chivita. 2012. "Analisis Sistem Pemberian Kredit Usaha Rakyat (Kur) Pada Pt. Bank Tabungan Negara (Persero) Tbk Kantor Cabang Solo." In Sripsi Fakultas Ekonomi Universitas Sebelas Maret Surakarta, , 32-33.

Cahyono, Bahtiyar Adi. 2010. "Prosedur Pengajuan Kredit Pada Pd. Bpr Bkk Tasikmadu Cabang Colomadu Kabupaten Karanganyar Tugas." In Sripsi Fakultas Ekonomi Universitas Sebelas Maret Surakarta, , 22-23.

Haryana, Gani. 2014. "Analisis Kredit Usaha Rakyat (Kur) Pada Bank Bri Unit Tabek Patah Cabang Batusangkar Sumatera Barat." : 1-8. 
Kasmir. 2014. "Dasar-Dasar Perkreditan.” In , 1-23.

Amelia, L., \& Marlius, D. (2018). Pengendalian Kredit Dalam Upaya Menciptakan Bank Yang Sehat Pada PT. Bank Pembangunan Daerah Sumatera Barat Cabang Utama Padang. https://doi.org/10.31227/osf.io/kpc64

Respatiningsih, Hesti. 2011. "Manajemen Kredit Usaha Mikro Kecil Dan Menengah (Umkm).” Jurnal Manajemen Dan Bisnis: 31-44.

Shanjaya, A. R., \& Marlius, D. (2017). Peranan Laporan Keuangan Dalam Kebijaksanaan Pemberian Kredit Kepada Calon Nasabah Pada PT. BPR Batang Kapas. https://doi.org/10.31227/osf.io/uxmg6

Sudrajat, Jajat. 2014. "Pengembangan Sistem Informasi Kredit Usaha Rakyat Di Pt . Bpr Nusamba Tanjungsari." Jurnal Computech \& Bisnis 8(2): 80-91.

Suhardi, Gunarto. 2016. "Prosedur Penyaluran Dan Pengelolaan Kredit Usaha Rakyat (Kur) Pada Bank Nagari Cabang Ujung Gading Kabupaten Pasaman Barat." Jurnal Aspek Hukum Dalam Bisnis: 22.

Widiastuti, Rahayu. 2017. “Apakah Kredit Usaha Rakyat (Kur) Berdampak Pada Kinerja Usaha (Studi Pada Umkm Makanan Ringan Di Kota Salatiga).” Jurnal Visi Manajemen 2(2): 100-115.

Wijaya, Frenky Tanni. 2016. "Pengaruh Program Kredit Usaha Rakyat (Kur) Pt. Bank Rakyat Indonesia Unit Teluk Panji Terhadap Kehidupan Sosial Ekonomi Masyarakat Di Desa Teluk Panji Kecamatan Kampung Rakyat Kabupaten Labuhanbatu Selatan.” : 1-12. 